\title{
Maternal resources and household food security: evidence from Nicaragua
}

\author{
Kammi K Schmeer ${ }^{1, *}$, Barbara A Piperata ${ }^{2}$, Andrés Herrera Rodríguez ${ }^{3}$, \\ Virgilio Mariano Salazar Torres ${ }^{3,4}$ and Francisco José Centeno Cárdenas ${ }^{3}$ \\ 'Department of Sociology, The Ohio State University, 238 Townshend Hall, 1885 Neil Avenue Mall, Columbus, \\ $\mathrm{OH} 43210$, USA: ${ }^{2}$ Department of Anthropology, The Ohio State University, Columbus, OH, USA: ${ }^{3}$ Centro de \\ Investigación en Demografía y Salud (CIDS), Universidad Nacional Autónoma de Nicaragua - León (UNAN-León), \\ León, Nicaragua: ${ }^{4}$ Epidemiology and Global Health, Umeå University, Umeå, Sweden
}

Submitted 13 December 2013: Final revision received 6 November 2014: Accepted 16 November 2014: First published online 7 January 2015

\begin{abstract}
Objective: Women (especially mothers) are theorized as critical to reducing household food insecurity through their work and caregiver roles. The present study tests these assumptions, assessing how maternal economic and social resources are associated with food insecurity in households with young children. Design: Data from a population-based sample of households was collected in León, Nicaragua ( $n$ 443). Data include a newly validated measure of household food insecurity (ELCSA), maternal resource measures, and household economic status and demographics. Regression analysis tests the statistical associations $(P<0.05)$ of maternal resources with household, adult-specific and child-specific food insecurity.

Setting: Municipality of León, Nicaragua.

Subjects: Households with children aged 3-11 years in rural and urban León.

Results: Only $25 \%$ of households with young children were food secure, with $50 \%$ mildly food insecure and $25 \%$ moderately/severely food insecure. When mothers contributed substantially to household income, the odds of moderate/severe household food insecurity were $34 \%$ lower than when their spouse/partner was the main provider. The odds of food insecurity were $60 \%$ lower when mothers managed household money, $48 \%$ lower when mothers had a secondary ( v. primary) education, $65 \%$ higher among single mothers and 16\% lower with each indicator of social support. Results were similar for adult- and child-specific food insecurity.

Conclusions: This research provides new evidence that maternal economic and social resources are important for reducing household food insecurity and adultand child-specific food insecurity. Women's social status, social support and access to economic resources need to be enhanced as a part of policies aimed to reduce food insecurity in high-poverty settings.
\end{abstract}

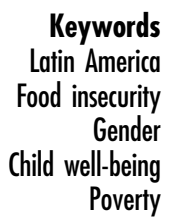

Food insecurity is a critical public health problem, with one in eight people around the world lacking consistent access to food to meet their needs for a healthful life ${ }^{(1)}$ The food insecure often have diets that are less diverse ${ }^{(2,3)}$ and of lower energy content, leading to poorer nutritional status $^{(4,5)}$ and increased rates of child illness ${ }^{(6)}$. Further, there is mounting evidence that household food insecurity is associated with poor mental health ${ }^{(7)}$ and maternal distress $^{(6)}$. Thus, food insecurity poses a serious threat to individual well-being and undermines national-level productivity, particularly in low-income countries where a substantial number of people are food insecure.
Food insecurity is often measured at the household level, where food is purchased, produced, prepared and distributed. Understanding the social determinants of household food insecurity is important for designing public health policies and programmes to increase individuals' access to food in poor settings. Lack of economic resources is the most studied risk factor for household food insecurity in low-income countries ${ }^{(8-10)}$ and is important for food security as households increasingly rely on purchased foods throughout the developing world ${ }^{(11)}$. However, not all poor households are food insecure and factors other than household income may be important 
determinants of food insecurity, as a recent review of research suggests ${ }^{(12)}$.

The present study expands our understanding of the determinants of food insecurity in low-income countries by focusing on mothers' access to economic and social resources as key to reducing food insecurity in households with children. This is a critical area of research, since policy makers have designed social policies in low-income countries based on research that indicates income in the hands of women promotes household well-being more than when controlled by men ${ }^{(13)}$. Most relevant to the present study, research on cash cropping in Africa reveals that food availability and dietary energy adequacy are better in female-headed households compared with maleheaded households ${ }^{(14,15)}$. Another study, of married mothers in the Philippines, suggests that mothers' access to and control over household income increases household spending on food ${ }^{(16)}$. A recent study also indicates low maternal education is associated with household food insecurity in rural Honduras ${ }^{(17)}$, and in rural Tanzania households have higher seasonal food insecurity when mothers report less social support ${ }^{(3)}$. Together these studies suggest the potentially important role of maternal economic and social resources for preventing household food insecurity, but no study to date has assessed associations between household food insecurity and multiple aspects of mothers' economic and social resources, net of household economic status and demographics.

Also lacking is research on whether maternal resources affect adult- and child-specific food insecurity. There is some evidence that children are buffered from food insecurity more than adults ${ }^{(11,18,19)}$ and that household socio-economic status may protect children more than adults from food insecurity ${ }^{(20)}$. Given research that indicates women use household resources to protect child well-being more than do men ${ }^{(16,21,22)}$, maternal resources may be particularly important for reducing food insecurity among children. However, we were unable to find studies assessing maternal resource effects on adult- and childspecific food insecurity in any setting.

The present study addresses these research gaps, increasing our understanding of how multiple types of maternal resources are associated with household and adult/child-specific food insecurity in urban and rural areas of León, Nicaragua.

\section{Nicaragua}

Across multiple indicators, Nicaragua is characterized as one of the poorest countries in Latin America with $45 \%$ of the population living on less than US\$ 1 per day ${ }^{(23)}$. Reports from aid agencies state that 'food insecurity is one of the most critical development challenges facing Nicaragua $^{,(23)}$ and that this is due to lack of access to affordable food rather than low food availability. Most recently, the 'Global Food Crisis' (2006-2008) and ongoing fluctuations in global markets continue to increase the cost of and instability in prices of basic food goods in Nicaragua ${ }^{(24)}$. As a result, it is estimated that almost $30 \%$ of the Nicaraguan population is undernourished ${ }^{(23)}$, and women and children are most vulnerable to food insecurity and undernutrition $^{(24)}$.

In addition to high poverty and risks of food insecurity, gender dynamics in Nicaragua make this an important setting for understanding the relationship between maternal access to resources and food insecurity. Gender roles and poverty come together in Nicaragua to reduce women's power and access to economic resources while placing the burden on them to provide for their children. Recent statistics indicate low marriage rates among women ( $48 \%$ legally married), a high proportion of female-headed households (30\%) and high female labour force participation (48\%) compared with other Latin American countries, such as Mexico ${ }^{(25)}$.

\section{Study bypotbeses}

In this setting, and following past research, we hypothesize that household food insecurity will be lower when mothers have higher levels of economic and social resources. We measure mothers' economic resources through their reported contributions to household income and role in managing household income. Social resources include maternal level of education, union status and reported social support. We expect lower household food insecurity when mothers contribute economically to the household and have greater control over managing household financial resources. Higher maternal education is expected to be associated with lower food insecurity due to research demonstrating mothers with higher education have more social and human capital that can be used to benefit child well-being ${ }^{(26)}$ and reduce household food insecurity ${ }^{(17)}$. Married and cohabiting mothers are hypothesized to have higher household food security than those without a partner due to the financial, emotional, time and other key resources that may be provided by partners. Maternal social support is expected to be negatively associated with household food insecurity by providing sources of help in difficult times ${ }^{(3)}$. We further hypothesize that these maternal resources may be more important for reducing food insecurity among children than among adults, given the role of mothers as primary caregivers in Nicaragua and past research suggesting that children are protected from food insecurity more than adults in poor households ${ }^{(20)}$.

\section{Methods}

\section{Study design}

The study was designed to increase our knowledge of the relationships among maternal resources, poverty and food insecurity in households with children. Our research 
centres around the household as a key institution where individuals purchase, produce, prepare, distribute and consume food on a daily basis. Young children are particularly dependent on household resources and food for adequate nutrition, making this an important population within which to understand food insecurity. The target population for the study was households with at least one child who was not breast-feeding but still highly dependent on the household for food (i.e. between the ages of 3 and 11 years).

The municipality of León was selected as the study site due to the ongoing Health and Demographic Surveillance System (HDSS) León, which provided a sampling frame and local collaborators for the study. León is the second largest municipality ( 180000 inhabitants) in Nicaragua and is $70 \%$ urban. Forty per cent of the urban population lives in poverty; poverty is more severe and common in the rural areas of León, where $70 \%$ of residents are poor, land is concentrated in the hands of the elite and households are further from sources of affordable food ${ }^{(27)}$. Although food insecurity and malnutrition are estimated to be moderate in León compared with other municipalities in the country ${ }^{(28)}$, León bears the legacy of the cotton agro-industry, which boomed and then busted in the 1990s, leaving many rural farmers landless and urban labourers unemployed. There is little remaining tradition of growing one's own food in León, which is substantiated by our data that indicate $92 \%$ of household food is purchased (97\% in urban and $84 \%$ in rural areas).

\section{Study sample}

The study sample was selected from the HDSS-León, a representative sample of over 10000 households in the municipality of León. The HDSS-León has been collected by the Center for Health and Demographic Research (CIDS) at the National Autonomous University of Nicaragua - León (UNAN-León) since $1993^{(29)}$. In 2009, the HDSS sample was refreshed to reflect the current population of the municipality, which served as our sampling frame. In collaboration with statisticians from CIDS, a power analysis was conducted estimating levels of food insecurity at $50 \%$ and an error rate of $5 \%$. An additional $10 \%$ was added to account for the cluster design effect and $15 \%$ for potential non-response. This yielded a target sample of 500 households. We randomly selected households from the HDSS who had children between the ages of 0 and 8 years in 2009, and would thus be in our target population of households with a child aged between 3 and 11 years in 2012. This process was conducted separately for rural and urban samples, with urban defined as the administrative boundaries used in the original HDSS sample. Because the city has grown since the baseline survey, we oversampled rural households ( $n$ 200) to ensure we would have an adequate number of rural households that were not part of the overgrowth of the urban centre. The study response rate was high (94\%), resulting in a loss of only thirty households. In an additional twenty-seven households mothers were absent; these households were not included in the analytical sample ( $n$ 443).

\section{Data collection}

Over a 3-week period, Ohio State University researchers worked with CIDS researchers to select and train ten local women who made up five interview teams, each consisting of one nurse and one social worker. The women were trained in research ethics, the collection of anthropometric and anaemia biomeasures, and the administration of the questionnaire. As the interviewers were all local women, their advice was sought in the wording of questions and their suggestions integrated into the final version of the survey instrument. The data entry personnel and field coordinators were also included in these trainings and were further trained in quality control of the completed surveys and data entry. Once the quantitative survey instrument was developed, the wording of the questions and answer choices was further refined through testing in focus groups. The final instrument was then field tested through interviews with women in randomly selected households outside the study sample within the study area.

The final questionnaire was administered to the sample households with mothers as the respondents. If the mother was permanently absent an alternative respondent was used. The study was conducted according to the guidelines laid down in the Declaration of Helsinki and all procedures involving human subjects were approved by the Institutional Review Boards at The Ohio State University and UNAN-León. Verbal informed consent was witnessed and formally recorded for all participants. During the course of the interview, interviewees were reminded of their right to refuse to respond to any study question or terminate the interview. Interviewers returned to households as needed to complete the interviews and ensure high-quality data. Throughout the data collection process quality control was ensured through supervision by coordinators both in the field and in the data entry process.

\section{Measures}

\section{Dependent variables}

Household food insecurity was assessed through the recently validated Nicaraguan version of the Latin American Food Security Questionnaire (ELCSA), which consists of fifteen questions related to concerns with and experiences of food scarcity due to lack of sufficient money or resources during the past 3 months. The original perceived household food insecurity questionnaire was developed in the USA ${ }^{(30)}$ and subsequently adapted internationally. The Latin 
American version (ELCSA), validated across the region as a reliable indicator of perceived food security ${ }^{(31-33)}$, was field tested and adapted for use in Nicaragua. Three dependent variables were created from the ELCSA: (i) household food insecurity, measured by the number of affirmative responses to the fifteen questions; (ii) adult food insecurity, measured by the number of affirmative responses to five adult-oriented questions; and (iii) child ( $<18$ years) food insecurity, measured by the number of affirmative responses to seven child-oriented questions. Following existing research, household food insecurity was converted to a dichotomous measure, with fewer than six affirmative responses indicating mild or no food insecurity and six or greater affirmative responses indicating moderate to severe food insecurity ${ }^{(1)}$. Given the lack of research separating out the adult- and child-specific questions in developing countries, no established cut-off has been set. These measures were considered as continuous outcomes to capture variation in the level of adultand child-specific food insecurity.

\section{Independent variables}

Maternal resources were assessed through five measures: two measures of economic resources and three measures of social resources. The first maternal economic resource variable measured who contributed the most money to the household: the mother alone, spouse/partner alone, mother equally with spouse/partner, or another person. This variable was collapsed into a three-category variable indicating households where the mother contributed the most or equal to their spouse, the spouse contributed the most or some other person contributed the most to household income. The second maternal economic variable assessed who usually manages household money: the mother alone, mother equally with her spouse, spouse alone, or some other household member. A dummy variable was created to reflect households where mothers had full control or equally shared control with their spouse $(=1)$, compared with those where mothers had little role in managing household money.

Three variables were used to capture maternal social resources: maternal education, maternal union status and maternal social support. Education was categorized as primary level or less, secondary level (high school) and more than high school. Maternal union status was categorized as married, cohabiting (residential, unmarried partner) or no partner (including never-married, separated, divorced and widowed mothers). Further disaggregation of the 'no partner' category did not change the results. Level of maternal social support was evaluated through thirteen questions. The first seven asked about instrumental support, such as whether the mother had someone from whom she could obtain help when needed (e.g. borrow money, give food, take care of children, help with housework, etc.). The other six related to whether the mother had someone who supported her emotionally (e.g. listened to her, relaxed with her, gave her advice, etc.). Affirmative answers were summed and the variable was used as a continuous measure of social support ranging from 0 to 13 .

To consider the importance of maternal resources net of household resources, four measures of household economic resources were included: a wealth index, access to land, receipt of migration remittances and receipt of government cash assistance. The household wealth index was calculated using principal component analysis, integrating measures of household assets, housing quality, water availability and type of sanitation into a score for each household. The first wealth component score (eigenvalue >3) was included as the household wealth measure. This method has been shown to be an efficient way to control for economic status in developing country households ${ }^{(34)}$. Access to land was measured as a dummy variable indicating if the household had land that could be used for crops or animal pasture. Migration remittances were defined as economic help given to the household in the past 6 months by family members or friends living outside León or Nicaragua, and measured as a yes/no dummy variable. Government cash assistance received regularly by any household member was coded as a dummy variable.

Control variables included: maternal age, mother's pregnancy status (pregnant, not pregnant), presence of residential grandparent(s) (one or more grandparent living in household, no grandparent in household), age of the youngest child and number of children in the household. We also included urbanicity (urban, rural) and three community dummy variables (Sutiaba, Perla and Mántica) that were defined by administrative boundaries. The urbanicity variable controls for differences in women's resources and access to food in urban and rural areas, as well as the oversampling of rural households. We included community dummy variables to control for unobserved differences at the community level that may affect both mothers' access to resources and household food insecurity.

\section{Statistical analysis}

The household food insecurity models used a dichotomous dependent variable (moderate/severe household food insecurity) and were estimated with multivariate logistic regression. The results are presented as odds ratios (exponentiated coefficients). For the adult- and childspecific models, the dependent variables are count data that are over-dispersed, requiring negative binomial regression analysis ${ }^{(35)}$. Models were estimated using maximum likelihood and the results are presented as incidence risk ratios (exponentiated coefficients). Standard errors were corrected for clustering among household within each community, and confidence intervals are shown in the tables. Statistical significance of all variables 
was assessed through two-tailed $z$ tests of $P<0.05$. In presenting the descriptive results we show weighted means and percentages that account for oversampling of rural households. In the regression models, controlling for urbanicity accounts for oversampling so weights were not needed ${ }^{(36)}$.

\section{Results}

Table 1 presents summary results of the levels of perceived household food insecurity. Mean total food insecurity (number of affirmative responses) was 3.5 and $25 \%$ of the households were moderately to severely food insecure (see Table 1). Sixty-six per cent of households reported worrying that food would run out and $25 \%$ reported running out of food in the past 3 months (data not shown). The adultand child-specific questions reflect the strategies used to cope with low food availability. The mean score for both adult and child food insecurity was 1 (see Table 1). Despite these low averages, $35 \%$ of households reported that an adult ate less than he/she should have and $26 \%$ that an adult was hungry but did not eat at least once in the past 3 months due to insufficient money to purchase food (data not shown). The most common child experiences were decreasing the amount of food served to a child (22\%), children having little dietary diversity (21\%) and a child eating less than he/she should have (19\%). Ten per cent of households reported that a child skipped a meal, $11 \%$ reported a child felt hungry but did not eat and $6 \%$ reported that a child had gone a whole day without eating at least once in the past 3 months. Rural households had significantly higher mean household, adult and child food insecurity scores than urban households. Given our oversample of rural households, the percentages presented here were weighted to generalize to the target population (households in León with young children).

Table 2 provides descriptive statistics for our independent variables of interest and control variables, also weighted to account for the oversample of rural households. Although over half of the sample mothers worked for pay (54\%), only $35 \%$ of the mothers contributed as much or more than their spouse to household income (20\% of mothers reported contributing more to household income than their spouse or any other member).
Despite their relatively low economic contributions, in the majority of households ( $72 \%$ ) mothers played a significant role in managing household economic resources: $58 \%$ reported being the primary money managers and 13\% reported managing household money equally with their spouse/partner. Mothers in our sample had mixed access to social resources: they reported relatively low education (35\% primary or below) and high rates of single motherhood ( $21 \%$ of the sample), but high social support (an average of 10 points out of a possible 13). In terms of household economic status, households averaged nine of seventeen possible household assets $($ median $=9$ ), relatively few had access to land (16\%), $14 \%$ received remittances in the past 6 months and only $4 \%$ received regular cash support from the government.

Table 3 reports the results of regression models estimating the associations between maternal resources and a dichotomous measure of moderate to severe household food insecurity. All results are presented as odds ratios, with ratios below 1.00 indicating a decrease and those above 1.00 an increase in food insecurity. Models are shown first with the basic control and household economic variables traditionally associated with food insecurity, followed by models incorporating the maternal resource measures.

Model 1 indicates a significantly higher odds of food insecurity in rural compared with urban households, even when controlling for household demographics and community fixed effects. However, this difference disappears when household economic status is taken into account (model 2). Not surprisingly, higher household wealth and receipt of remittances were associated with lower odds of household food insecurity (Table 3, model 2).

Model 3 shows the associations between maternal economic and social resources and household food insecurity controlling for household economic resources, demographics and community effects. Compared with households where spouses alone provided the main source of income, households where the mother contributed equally or more than her spouse had a $34 \%$ lower risk of moderate/severe food insecurity. Households where mothers managed household money by themselves or equally with their spouses had a $60 \%$ lower risk of moderate/severe food insecurity compared with households where the spouse or other member manages the

Table 1 Weighted means of perceived household food insecurity in past 3 months. León, Nicaragua ( $n$ 443)

\begin{tabular}{|c|c|c|c|c|}
\hline Variable & Mean or \% & SD & Min. & Max \\
\hline \multicolumn{5}{|l|}{ Continuous food insecurity measures } \\
\hline Total affirmative responses & 3.50 & $4 \cdot 15$ & 0 & 15 \\
\hline Total adult score & $1 \cdot 24$ & 1.72 & 0 & 5 \\
\hline Total child score & 1.03 & 1.91 & 0 & 7 \\
\hline \multicolumn{5}{|l|}{ Categorical food insecurity measures } \\
\hline Household food secure (0 affirmative responses; \%) & 25 & & & \\
\hline Household mildly food insecure (1-5 affirmative responses; \%) & 50 & & & \\
\hline Household moderately or severely food insecure ( $>5$ affirmative responses; \%) & 25 & & & \\
\hline
\end{tabular}


Table 2 Weighted descriptive statistics for independent variables. León, Nicaragua ( $n$ 443)

\begin{tabular}{|c|c|c|c|c|}
\hline Variable & $\%$ or Mean & SD & Min. & Max. \\
\hline \multicolumn{5}{|l|}{ Maternal economic resources } \\
\hline Mother contributes most to $\mathrm{HH}$ income (self or equally with spouse; \%) & 35 & & & \\
\hline Spouse alone contributes most to $\mathrm{HH}$ income (\%) & 47 & & & \\
\hline Other person contributes most to $\mathrm{HH}$ income (\%) & 18 & & & \\
\hline Mother manages HH money (self or equally with spouse; \%) & 72 & & & \\
\hline \multicolumn{5}{|l|}{ Maternal social resources } \\
\hline Mother primary education or less (\%) & 35 & & & \\
\hline Mother secondary education (\%) & 44 & & & \\
\hline Mother higher than secondary education (\%) & 21 & & & \\
\hline Mother married (\%) & 42 & & & \\
\hline Mother cohabiting (\%) & 37 & & & \\
\hline Mother single (\%) & 21 & & & \\
\hline Total social support (number of affirmative responses) & $10 \cdot 3$ & $2 \cdot 87$ & 0 & 13 \\
\hline \multicolumn{5}{|l|}{$\mathrm{HH}$ economic resources } \\
\hline Number of $\mathrm{HH}$ assets† & $9 \cdot 4$ & $3 \cdot 10$ & 0 & 17 \\
\hline Access to land for crops/pasture (\%) & 16 & & & \\
\hline Received remittances (in past 6 months; \%) & 14 & & & \\
\hline Receives government cash assistance (\%) & 4 & & & \\
\hline \multicolumn{5}{|l|}{ Demographic characteristics } \\
\hline Maternal age (years) & $31 \cdot 3$ & $6 \cdot 75$ & 18 & 61 \\
\hline Mother pregnant & 3 & & & \\
\hline No grandparents in $\mathrm{HH}(\%)$ & 47 & & & \\
\hline Age of youngest child in $\mathrm{HH}$ (years) & 3.9 & $2 \cdot 64$ & 0 & 10 \\
\hline Number of children in $\mathrm{HH}$ & $3 \cdot 2$ & 1.68 & 1 & 14 \\
\hline Urban (\%) & 60 & & & \\
\hline
\end{tabular}

$\mathrm{HH}$, household.

†Wealth index (principal components score of assets, housing quality, sanitation and animals) rather than number of assets used in regression analysis.

Table 3 Associations of maternal resources with moderate/severe household food insecurity. León, Nicaragua $(n$ 443)

\begin{tabular}{|c|c|c|c|c|c|c|}
\hline \multirow[b]{2}{*}{ Independent variable } & \multicolumn{2}{|c|}{ Model 1} & \multicolumn{2}{|c|}{ Model 2} & \multicolumn{2}{|c|}{ Model 3} \\
\hline & OR & $95 \% \mathrm{Cl}$ & OR & $95 \% \mathrm{Cl}$ & OR & $95 \% \mathrm{Cl}$ \\
\hline \multicolumn{7}{|l|}{ Maternal economic resources } \\
\hline Mother contributes most to $\mathrm{HH}$ income $\dagger$ & & & & & $0.66^{\star \star}$ & $0.55,0.80$ \\
\hline Other person contributes most to $\mathrm{HH}$ income† & & & & & 0.99 & $0.23,4.23$ \\
\hline Mother manages $\mathrm{HH}$ income $\neq$ & & & & & $0.40^{\star *}$ & $0.24,0.66$ \\
\hline \multicolumn{7}{|l|}{ Maternal social resources } \\
\hline Secondary education§ & & & & & $0.53^{*}$ & $0.31,0.90$ \\
\hline Higher education§ & & & & & $0.62^{*}$ & $0.40,0.96$ \\
\hline Marriedll & & & & & $0.65^{\star}$ & $0.45,0.93$ \\
\hline Cohabiting\| & & & & & $0.64^{*}$ & $0.42,0.98$ \\
\hline Social support & & & & & $0 \cdot 84^{* *}$ & $0.83,0.85$ \\
\hline \multicolumn{7}{|l|}{$\mathrm{HH}$ economic resources } \\
\hline Wealth score & & & $0.67^{\star \star}$ & $0.57,0.80$ & $0 \cdot 71^{* *}$ & $0.62,0.82$ \\
\hline Access to crop/pasture land & & & 0.56 & $0.20,1.55$ & 0.52 & $0.19,1.43$ \\
\hline Received remittances & & & $0.35^{\star \star}$ & $0.21,0.58$ & 0.36 & $0.13,1.00$ \\
\hline Receives government cash support & & & 0.72 & $0.44,1.17$ & 1.36 & $0.97,1.90$ \\
\hline \multicolumn{7}{|l|}{ Controls } \\
\hline Maternal age & $0.98^{*}$ & $0.97,1.00$ & $0.99^{\star \star}$ & $0.98,1.00$ & 0.99 & $0.98,1.01$ \\
\hline Mother pregnant & 0.66 & $0.28,1.52$ & 0.84 & $0.29,2.47$ & 0.78 & $0.12,5 \cdot 17$ \\
\hline No grandparents in $\mathrm{HH}$ & $1.64^{\star *}$ & $1 \cdot 27,2 \cdot 12$ & 1.30 & $0.81,2.11$ & 1.38 & $0.93,2.05$ \\
\hline Age of youngest child & 1.02 & $0.90,1.16$ & 1.05 & $0.92,1.19$ & 1.07 & $0.99,1.16$ \\
\hline Number of children in $\mathrm{HH}$ & $1 \cdot 21^{\star *}$ & $1.12,1.32$ & $1 \cdot 16^{\star *}$ & $1 \cdot 10,1.22$ & 1.19 & $0.98,1.44$ \\
\hline Urban area & $0.29^{\star *}$ & $0.17,0.50$ & 0.95 & $0.65,1.40$ & 0.69 & $0.33,1.44$ \\
\hline Sutiaba community & $2 \cdot 84^{\star \star}$ & $2.20,3.67$ & $2 \cdot 47^{\star \star}$ & $1.96,3.12$ & $2 \cdot 88^{\star *}$ & $1.95,4.25$ \\
\hline Perla community 9 & $1 \cdot 76^{\star \star}$ & $1.75,1.77$ & $1.98^{\star \star}$ & $1.82,2.15$ & $2 \cdot 02^{\star *}$ & $1.72,2.37$ \\
\hline Constant & $0.26^{\star *}$ & $0.12,0.59$ & $0 \cdot 13^{\star \star}$ & $0.067,0.26$ & $2 \cdot 60^{\star *}$ & $1.74,3.89$ \\
\hline Log likelihood & \multicolumn{2}{|c|}{-234} & \multicolumn{2}{|c|}{-218} & \multicolumn{2}{|c|}{-198} \\
\hline
\end{tabular}

$\mathrm{HH}$, household.

${ }^{*} P<0.05,{ }^{* *} P<0.01$.

†Reference group: spouse alone contributes most money to $\mathrm{HH}$.

¥Reference group: spouse or other person manages $\mathrm{HH}$ money.

$\S$ Reference group: primary education or less.

IIReference group: single, divorced, separated or widowed.

ףReference group: Mántica community. 
Table 4 Associations of maternal resources with adult-specific and child-specific food insecurity. León, Nicaragua ( $n$ 443)

\begin{tabular}{|c|c|c|c|c|}
\hline \multirow[b]{2}{*}{ Independent variables } & \multicolumn{2}{|c|}{ Adult food insecurity } & \multicolumn{2}{|c|}{ Child food insecurity } \\
\hline & IRR & $95 \% \mathrm{Cl}$ & IRR & $95 \% \mathrm{Cl}$ \\
\hline \multicolumn{5}{|l|}{ Maternal economic resources } \\
\hline Mother contributes most to $\mathrm{HH}$ income† & $0.72^{\star \star}$ & $0.65,0.79$ & $0.64^{\star \star}$ & $0.59,0.69$ \\
\hline Other person contributes most to $\mathrm{HH}$ incomet & 0.83 & $0.48,1.41$ & 0.88 & $0.41,1.86$ \\
\hline Mother manages $\mathrm{HH}$ income $\ddagger$ & $0.64^{\star \star}$ & $0.48,0.86$ & 0.70 & $0.42,1 \cdot 15$ \\
\hline \multicolumn{5}{|l|}{ Maternal social resources } \\
\hline Secondary education§ & $0.66^{\star \star}$ & $0.51,0.86$ & $0.66^{\star \star}$ & $0.59,0.75$ \\
\hline Higher education§ & $0.64^{\text {** }}$ & $0.55,0.75$ & $0.49^{* *}$ & $0.36,0.65$ \\
\hline Married\| & $0.80^{*}$ & $0.66,0.96$ & 0.83 & $0.67,1.04$ \\
\hline Cohabiting\| & 0.85 & $0.71,1.02$ & 0.76 & $0.51,1.12$ \\
\hline Social support & $0.90^{\star *}$ & $0.86,0.93$ & $0.89^{\star \star}$ & $0.86,0.92$ \\
\hline \multicolumn{5}{|l|}{$\mathrm{HH}$ economic resources } \\
\hline Wealth score & $0.83^{\star *}$ & $0.74,0.92$ & $0.77^{\star *}$ & $0.67,0.88$ \\
\hline Access to crop/pasture land & $0.62^{*}$ & $0.43,0.91$ & $0.54^{\star *}$ & $0.37,0.79$ \\
\hline Received remittances & $0.69^{\star *}$ & $0.53,0.90$ & $0.56^{\star}$ & $0.33,0.93$ \\
\hline Receives government cash support & $0.66^{\star}$ & $0.47,0.92$ & 1.01 & $0.58,1.76$ \\
\hline \multicolumn{5}{|l|}{ Controls } \\
\hline Maternal age & 0.99 & $0.98,1.01$ & 1.01 & $0.96,1.06$ \\
\hline Mother pregnant & $1.54^{\star *}$ & $1.36,1.74$ & 1.34 & $0.68,2.64$ \\
\hline No grandparents in $\mathrm{HH}$ & 0.85 & $0.57,1.26$ & 0.92 & $0.47,1.79$ \\
\hline Age of youngest child & $1.04^{*}$ & $1.00,1.09$ & 1.07 & $1.00,1.14$ \\
\hline Number of children in household & $1 \cdot 12^{\star \star}$ & $1.06,1.18$ & $1 \cdot 12$ & $0.99,1.28$ \\
\hline Urban area & $0.90^{\star}$ & $0.81,0.99$ & 0.79 & $0.46,1.35$ \\
\hline Sutiaba community $\mathbb{I}$ & $1 \cdot 75^{\star \star}$ & $1.36,2.25$ & $1.98^{\star *}$ & $1.50,2.62$ \\
\hline Perla community I & $1.73^{\star *}$ & $1.39,2.17$ & $2.02^{* *}$ & $1.47,2.76$ \\
\hline Constant & \multirow{2}{*}{\multicolumn{2}{|c|}{$3.62,5.95$}} & $2 \cdot 13$ & $0.50,9.06$ \\
\hline Log likelihood & & & \multicolumn{2}{|c|}{-548} \\
\hline
\end{tabular}

IRR, incidence risk ratio; $\mathrm{HH}$, household

${ }^{\star} P<0.05,{ }^{* *} P<0.01$.

†Reference group: spouse alone contributes most money to $\mathrm{HH}$.

$\ddagger$ Reference group: spouse or other person manages $\mathrm{HH}$ money.

$\S$ Reference group: primary education or less.

IReference group: single, divorced, separated or widowed.

ๆReference group: Mántica community.

household money (Table 3, model 3). In terms of social resources, maternal education, married or cohabiting union status and social support were all associated with lower odds of household food insecurity net of household economic status, demographics and community control variables. For example, households where mothers had a secondary education had $47 \%$ lower odds of moderate/ severe household food insecurity than households where maternal education was low (primary or below). Households with married or cohabiting mothers had 35\% and $36 \%$ lower odds of being moderately/severely food insecure, respectively, compared with single-mother households. Finally, each point increase in maternal social support was associated with $16 \%$ lower odds of moderate/severe household food insecurity (see Table 3, model 3).

Table 4 shows the results (presented as incidence rate ratios) of the adult and child food insecurity models. Maternal economic contribution to the household was important for both adult and child food security, reducing the insecurity rates by $29 \%$ for adults and $36 \%$ for children, compared with households where the spouse was the main breadwinner. Having household money managed by the mother was also important, but only for reducing the incidence rate of adult food insecurity; it decreased the rate by $36 \%$ compared with households where the spouse or other household member was the main money manager. Among the maternal social resource variables, above primary maternal education was associated with significantly lower incidence of adult and child food insecurity compared with households with low maternal education (see Table 4). Although maternal union status had similar sized effects on adult and child food insecurity, the associations were not statistically significant in the child model (model 2). Maternal social support was significantly associated with lower incidence of food insecurity for both adults and children (Table 4, models 1 and 2).

The findings in Table 4 indicate significant associations between household economic status and adult- and childspecific food insecurity; household wealth, access to land and receipt of remittances significantly reduced the incidence of adult and child food insecurity. Although it appears government support was associated with adult food insecurity, this result should be viewed with caution given the low percentage of households receiving cash assistance (4\%). In sum, comparing models 1 and 2, the effects of maternal resources and household economic resources are similar for adult and child food insecurity. However, it should be noted that the model fit, indicated by the log likelihood, is better for the child-specific than the adult-specific models. 


\section{Discussion}

Our study aimed to assess the importance of maternal resources for reducing household food insecurity in households with children in León, Nicaragua. Despite León's location in the Central Pacific region, where food insecurity is estimated to be lower than in other areas of Nicaragua ${ }^{(28)}$, we found that the majority $(75 \%)$ of our sample households were food insecure and $25 \%$ reported moderate/severe food insecurity. It is important to note that these data were collected during a period of political, economic and environmental stability. Rates are likely to be higher with international food price increases, during agricultural droughts, following natural disasters, or under other conditions of political and economic upheaval.

The study empirically tested whether maternal economic and social resources are important determinants of household food insecurity, net of household economic status, demographic characteristics and community differences. Maternal measures included more typical social status indicators (maternal education, maternal union status), as well as less-studied indicators of mothers' access to and control over resources (contribution to household earnings, control over household economic resources) and extent of social support. We also considered adult and child food security separately to assess whether maternal resources mattered more for protecting children from food insecurity.

Our results suggested that mothers' larger economic contribution to household income was associated with lower household food insecurity. This is consistent with literature that finds mothers may gain respect and power within the household, and children have better nutritional status, when mothers make a substantial contribution to household income ${ }^{(37)}$. Maternal control over household spending significantly decreased the risk of moderate/ severe household food insecurity. This suggests that women's ability to direct household spending, regardless of who earns it, may affect household food security. This finding is in agreement with research that indicates women's control over spending household income increases spending on food in households with children ${ }^{(16)}$.

Findings regarding social resources indicated that higher maternal education was associated with lower food insecurity, consistent with the recent study in rural Honduras $^{(17)}$. It is important to note that we tested models using the household head's education and found no significant association with food insecurity. Because the household head's education is correlated with maternal education, it is difficult to estimate both in the same model, but the lack of significance of the household head's education in separate models suggests that maternal education, not the general social status of the household, matters for food insecurity. The odds of moderate or severe household food insecurity also was lower in married and cohabiting than single-mother households. Given controls for economic status, this suggests that the presence of a partner may help with food security in non-economic ways: by providing time, information and other resources important for securing food.

Finally, greater maternal social support was consistently associated with reduced odds of moderate or severe household food insecurity. Although some evidence from Tanzania supports this link between social support and food insecurity ${ }^{(3)}$, we know of no other study that assessed maternal social support and food insecurity in a Latin American setting. It should be noted that food insecurity can disrupt social interactions and lead to social isolation $^{(38)}$. This implies a potentially reciprocal relationship between maternal social support and household food insecurity that needs to be further explicated with longitudinal data.

The results from the adult- and child-specific food insecurity models also showed that maternal resources were associated with reports of reduced quality and/or quantity of individuals' food intake. Maternal economic contribution, management of household money, higher education and having a marital partner in the home all contributed to lower risk of food insecurity among adults in the household. All maternal resources, except mothers' control over household spending and maternal union status, were associated with reduced child-specific food insecurity. Maternal control over household spending may not be as important for child food security if children are generally protected from food restrictions by mothers through strategies other than managing household economic resources. The lack of a union status effect in the child-specific models may indicate that single and partnered mothers are equally able to protect children from food insecurity if given access to other key resources (education, social support and income), or that they are more likely to sacrifice their own (or other adults') food intake to buffer their children from food insecurity.

Several study limitations should be considered. First, the data are cross-sectional, reducing our ability to make causal inferences or assess the dynamics of household food insecurity over time and across seasons. Second, our measure of household food insecurity, although validated across settings, is limited by its design as a measure of perceived household food insecurity. This measure does not reflect actual intake or food availability. Past studies, however, have found significant correlation between this measure and the variety of foods consumed at the household level ${ }^{(39)}$. Third, our sample consists of households with young children in León and thus the results cannot be generalized to all households in Nicaragua. However, this sample represents a group of policy interest - households with children in a high-poverty setting - and the findings can inform efforts to improve food insecurity in similarly vulnerable households within Nicaragua.

Despite these limitations, the study informs the growing body of food insecurity literature by providing new 
empirical evidence supporting theories that mothers' access to resources is critical to reducing food insecurity in households with children. The significant associations of maternal social and economic resources with reduced food insecurity suggest that both women's reproductive/care and productive/work roles are important to address in reducing household food insecurity. As data become available, future research should focus on comparative studies across the Latin American region, where we know relatively little about the dynamics of food insecurity, and longitudinal studies of maternal resources and food insecurity over time.

Policy efforts to improve food insecurity in poor settings, such as León, should consider multiple strategies that improve women's access to and control over household economic resources. Such policies may include directing food aid to mothers rather than schools or households and cash assistance given to mothers. Although a national conditional cash transfer programme, Red de Protección Social, is in place in Nicaragua, this programme was not highly prevalent in our sample households, perhaps due to its limited geographic scope and fixed 3-year enrolment per$\operatorname{iod}^{(40)}$. Labour market policies, such as educational investments (particularly for girls and women), higher minimum wages and child-care support targeted at helping women enter and stay in the labour market, could be used to increase mothers' access to economic resources. These policies that promote investments in women may reduce household food insecurity more than policies that support traditional male-breadwinner families. Promoting social connections among mothers through neighbourhood, church or other social support groups may also help protect households from food insecurity. Finally, understanding food insecurity and the dynamics in unmarried mother households will be a critical area for future research in Nicaragua, and elsewhere, given the rising rates of single mothers and female-headed households in many areas of the developing world ${ }^{(41)}$.

\section{Acknowledgements}

Acknowledgements: The authors thank the following project collaborators from the CIDS at UNAN-León: Margarita Chévez Díaz, Armando Benito Camacho, Perla Zeledón Zeledón, Aleyda Fuentes Reyes, Carla Quiroz López and Napoleón Vásquez Álvarez. This work could not have been completed without the extraordinary effort of the field team members: Yasuara Rivas Narváez, Walquiria Orozco, Reyna Duarte Calderón, Yuvielka Martínez Suazo, Ana Olivares Torres, María Morales Vargas, Karla Espinoza Montalván, Gabriela Quintanilla Hernández and Silvia Medrano Áviles. The authors also thank the data entry personnel: Jasmin Fuentes Membreño, Luz Delgado Centeno, Blanca Chavarría García and Rene Lucía Delgado. Financial support: Partial funding for this research was provided by The Ohio State
University Office of Outreach and Engagement and Office of International Affairs. The Ohio State University Office of Outreach and Engagement and Office of International Affairs had no role in the design, analysis or writing of this article. Conflict of interest: None. Authorship: The study research questions and study design were jointly formulated by K.K.S. and B.A.P. with input from A.H.R. and V.M.S.T. K.K.S. and B.A.P. conducted staff trainings and A.H.R. and V.M.S.T. coordinated the data collection. Database was designed and data were cleaned by F.J.C.C. Data analysis was conducted by K.K.S. Writing of the article was conducted by K.K.S. with input from B.A.P. A.H.R. and V.M.S.T. assisted in reviewing and editing the manuscript. Etbics of buman subject participation: The study was conducted according to the guidelines laid down in the Declaration of Helsinki and all procedures involving human subjects were approved by the Institutional Review Boards at The Ohio State University and the UNAN-León. Verbal informed consent was witnessed and formally recorded for all participants, who were reminded during the interview of their right to refuse to respond to any study question or to terminate the interview.

\section{References}

1. Food and Agriculture Organization of the United Nations, International Fund for Agricultural Development \& World Food Programme (2013) The State of Food Insecurity in the World 2013. The Multiple Dimensions of Food Security. Rome: FAO

2. Becquey E, Martin-Prevel Y, Traissac P et al. (2010) The household food insecurity access scale and an indexmember dietary diversity score contribute valid and complementary information on household food insecurity in an urban West-African setting. J Nutr 140, 2233-2240.

3. Hadley C, Mulder MB \& Fitzherbert E (2007) Seasonal food insecurity and perceived social support in rural Tanzania. Public Health Nutr 10, 544-551.

4. Hackett M, Melgar-Quinonez H \& Alvarez MC (2009) Household food insecurity associated with stunting and underweight among preschool children in Antioquia, Colombia. Rev Panam Salud Publica 25, 506-510.

5. Widome R, Neumark-Sztainer D, Hannan PJ et al. (2009) Eating when there is not enough to eat: eating behaviors and perceptions of food among food-insecure youths. $A m \mathrm{~J}$ Public Health 99, 822-858.

6. Anderson LC, Tegegn A, Tessema F et al. (2012) Food insecurity, childhood illness and maternal emotional distress in Ethiopia. Public Health Nutr 15, 648-655.

7. Weaver LJ \& Hadley C (2009) Moving beyond hunger and nutrition: a systematic review of the evidence linking food insecurity and mental health in developing countries. Ecol Food Nutr 48, 263-284.

8. Hadley C, Linzer DA, Belachew T et al. (2011) Household capacities, vulnerabilities and food insecurity: shifts in food insecurity in urban and rural Ethiopia during the 2008 food crisis. Soc Sci Med 73, 1534-1542.

9. Naylor RL \& Falcon WP (2010) Food security in an era of economic volatility. Popul Dev Rev 36, 693-723.

10. Ruel MT, Garrett JL, Hawkes C et al. (2010) The food, fuel, and financial crises affect the urban and rural poor disproportionately: a review of the evidence. $J$ Nutr 140, issue $1,170 \mathrm{~S}-176 \mathrm{~S}$. 
11. Graham MA (2004) 'No somos iguales': the effect of household economic standing on women's energy intake in the Andes. Soc Sci Med 58, 2291-2300.

12. Nord M (2014) What have we learned from two decades of research on household food security? Public Health Nutr 17, 2-4.

13. Rawlings LB \& Rubio GM (2005) Evaluating the impact of conditional cash transfer programs. World Bank Res Obs 20, $29-55$.

14. Kiriti TW \& Tisdell C (2004) Commercial agriculture, marital status and other influences on food availability: a Kenyan case study. J Food Agric Environ 2, 141-148.

15. Levin CE, Ruel MT, Morris SS et al. (1999) Working women in an urban setting: traders, vendors and food security in Accra. World Dev 27, 1977-1991.

16. Schmeer KK (2005) Married women's resource position and household food expenditures in Cebu, Philippines. $J$ Marriage Fam 67, 399-409.

17. Ben-Davies ME, Kinlaw A, del Campo YE et al. (2014) Risk factors associated with the presence and severity of food insecurity in rural Honduras. Public Health Nutr 17, 5-13.

18. Oldewage-Theron W, Dicks E \& Napier C (2005) Poverty, household food security and nutrition: coping strategies in an informal settlement in the Vaal Triangle, South Africa. Public Health 120, 795-804.

19. Piperata BA, Schmeer KK, Hadley C et al. (2013) Dietary inequalities of mother-child pairs in the rural Amazon: evidence of maternal-child buffering? Soc Sci Med 96, 183-191.

20. Kuku O, Gundersen C \& Garasky S (2011) Differences in food insecurity between adults and children in Zimbabwe. Food Policy 36, 311-317.

21. Haddad L (1999) The income earned by women: impacts on welfare outcomes. Agric Econ 20, 135-141.

22. Thomas D (1990) Intra-household resource allocation: an inferential approach. J Hum Res 25, 635-664.

23. Sahley C, Crosby B, Nelson D et al. (2005) The Governance Dimensions of Food Insecurity in Nicaragua. Washington, DC: US Agency for International Development; available at http://pdf.usaid.gov/pdf_docs/PNADE106.pdf

24. Dhur A (2009) Impact of the Global Financial Crisis: Nicaragua Case Study. Rome: World Food Programme.

25. Massey D, Fischer M \& Capoferro C (2006) Gender and migration in Latin America: a comparative analysis. Int Migr 44, 1-29.

26. Vikram K, Vanneman R \& Desai S (2012) Linkages between maternal education and childhood immunization in India. Soc Sci Med 75, 331-339.

27. Instituto Nacional de Información de Desarrollo (2005) VIII Censo de Población y IV de Vivienda, Municipio de León. Managua: INIDE.
28. Dumazert P (2008) Análisis y cartografía de la vulnerabilidad a la inseguridad alimentaria y nutricional en Nicaragua. Rome: World Food Programme.

29. Pena R, Perez W, Melendez M et al. (2008) The Nicaraguan Health and Demographic Surveillance Site, HDSS-Leon: a platform for public health research. Scand J Public Health 36, 318-325.

30. Nord M (2009) Food Insecurity in Households with Children: Prevalence, Severity, and Household Characteristics. Economic Information Bulletin no. EIB-56. Washington, DC: US Department of Agriculture, Economic Research Service.

31. Gonzalez W, Jimenez A, Madrigal G et al. (2008) Development and validation of measure of household food insecurity in urban Costa Rica confirms proposed generic questionnaire. J Nutr 138, 587-592.

32. Guerra LDD, Espinosa MM, Bezerra ACD et al. (2013) Food insecurity in households with adolescents in the Brazilian Amazon: prevalence and associated factors. Cad Saude Publica 29, 336-349.

33. Melgar-Quinonez H \& Hackett M (2008) Measuring household food security: the global experience. J Phys Ther Sci 21, 27-37.

34. Filmer D \& Pritchett LH (2001) Estimating wealth effects without expenditure data - or tears: an application to educational enrollments in states of India. Demography 38, 115-132.

35. Long JS \& Freese J (2006) Regression Models for Categorical Dependent Variables Using STATA, 2nd ed. College Station, TX: Stata Press.

36. Pfeffermann D (1993) The role of sampling weights when modeling survey data. Int Stat Rev/Rev Int Stat 61, 317-337.

37. Engle PL (1993) Influences of mothers' and fathers' income on children's nutritional status in Guatemala. Soc Sci Med 37, 1303-1312.

38. Hadley C, Stevenson EGJ, Tadesse Y et al. (2012) Rapidly rising food prices and the experience of food insecurity in urban Ethiopia: impacts on health and well-being. Soc Sci Med 75, 2412-2419.

39. Melgar-Quiñonez H, Zubieta AC, Valdez E et al. (2005) Validación de un instrumento para vigilar la inseguridad alimentaria de la Sierra de Manantlán, Jalisco. Salud Publica Mex 47, 413-422.

40. Bradshaw S \& Viquez AQ (2008) Women beneficiaries or women bearing the cost? A gendered analysis of the Red de Proteccion Social in Nicaragua. Dev Change 39, 823-844.

41. DeRose L (2011) International Family Indicators. Global Family Structure. Charlottesville, VA: Social Trends Institute. 